\title{
Colgajos Locales en Reconstrucción Facial. Alternativas de Tratamiento
}

\author{
Local Flaps in Facial Reconstruction. Treatment Alternatives
}

\author{
Claudio Huentequeo M.., ${ }^{1,23}$; Saul Siso C. ${ }^{1}$; Alejandro Unibazo Z., ${ }^{1,4}$; Daniel Pino D. ${ }^{3}$; \\ Juan Pablo Alister H. ${ }^{2,4}$; Cristopher Mayer O. ${ }^{5}$ \& Sergio Olate ${ }^{1,6}$
}

\begin{abstract}
HUENTEQUEO, C. M.; SISO, S. C.; UNIBAZO, A. Z.; PINO, D. D.; ALISTER, J. P. H.; MAYER, C. O. \& OLATE, S. Colgajos locales en reconstrucción facial. Alternativas de tratamiento. Int. J. Odontostomat., 15(2):538-550, 2021.

RESUMEN: Los defectos faciales de piel son frecuentemente secuelas producto de carcinomas basoceulares, carcinomas espinocelulares, melanomas, grandes tumores benignos o traumatismos de tejidos blandos. Las unidades y subunidades estéticas de la cara, la textura y color de la piel, junto a otros parámetros deben ser considerados durante la planificación de la reconstrucción mediante colgajos locales. El objetivo de este artículo de revisión bibliográfica fue describir y definir las técnicas más relevantes en los de colgajos locales aplicados en la reconstrucción facial y sus algoritmos actuales, en relación con la unidad o subunidad facial involucrada; sus consideraciones estéticas y cirugía complementaria. Las unidades y subunidades estéticas de la cara se dividen en regiones de la frente, párpados, mejillas, nariz, labios y mentón. Los colgajos de rotación, en isla, de avance y transposición son la base para la mayoría de los colgajos faciales; los más conocidos según la zona donante son: el colgajo frontal, colgajo de rotación y avance de mejilla; colgajo cérvico-facial, y colgajos nasolabiales, entre otros. La elección del colgajo depende de la zona y la unidad estética facial involucrada, siendo importante elegir y usar las líneas, los surcos y márgenes de estas unidades cuando sea posible con el fin de mejorar los resultados estéticos y reducir la posibilidad de secuelas. La cirugía complementaria y los procedimientos estéticos pueden lograr un buen camuflaje de algunas complicaciones estéticas o secuelas.
\end{abstract}

PALABRAS CLAVE: colgajos locales, colgajos locales en reconstrucción facial, unidades estéticas faciales, cirugía reconstructiva facial, cáncer de piel facial

\section{INTRODUCCIÓN}

El trauma y el cáncer de la región facial causa diferentes tipos de secuelas, y su camuflaje estético es siempre un desafío. La reconstrucción facial se basa en conceptos estéticos, desarrollados y mejorados con los años. Las unidades y subunidades faciales, su textura, el color y la localización son factores relevantes para considerar en estos tipos de procedimientos (Hwang, 2014). La reconstrucción basada en colgajos locales es la técnica más usada en grandes defectos traumáticos o por cáncer de piel, con excelentes resultados (Van Leeuwen et al., 2015).
La anatomía facial es compleja y los colgajos locales están determinados por el aporte sanguíneo (Jowett \& Mlynarek, 2010), mientras que los nervios como el nervio facial son estructuras que delimitan estos colgajos y agregan complejidad a la reconstrucción (Cass \& Terella, 2019). La superficie de la piel varía según las diferentes regiones de la cara (Pepper \& Baker, 2013), siendo una consideración relevante para una reconstrucción estética. Además, el contorno y la laxitud de la cara es dependiente del sexo y la edad (Wo et al., 2021), permitiendo diversos grados

\footnotetext{
${ }^{1}$ Servicio de Cirugía Oral y Maxilofacial, Hospital Dr. Abraham Godoy Peña, Lautaro, Chile.

${ }^{2}$ Unidad de Cirugía Oral y Maxilofacial, Universidad de La Frontera, Temuco, Chile.

${ }^{3}$ Unidad de Cirugía Oral y Maxilofacial, Universidad de Los Andes, Santiago de Chile.

${ }^{4}$ Servicio de Cirugía Oral y Maxilofacial, Hospital Dr. Hernán Henríquez Aravena, Temuco, Chile.

${ }^{5}$ Servicio de Cirugía Oral y Maxilofacial, Hospital del Salvador, Santiago de Chile.

${ }^{6}$ Centro de Excelencia en Estudios Morfológicos y Quirúrgicos, Universidad de La Frontera, Chile.
} 
de movimiento del colgajo. Esto también depende de la unidad facial y la región comprendida. La reconstrucción estética de la cara requiere de cirujanos experimentados, que estén familiarizados con la diversidad de colgajos existentes, para elegir el más adecuado y resolver cada defecto de forma particular. Las técnicas de levantamiento de colgajos locales se basan principalmente en los colgajos tipo: los colgajos rotacionales, de traslación, de avance y de isla; así podemos ver diversos colgajos utilizados en las distinas regiones, siendo los más frecuentes, el colgajo frontal, colgajo de avance y rotación de mejilla, colgajos romboidales, cérvico-faciales, bilobulados, nasolabiales, entre otros (Yotsuyanagi et al., 2001; Colletti, 2012; Benoit et al., 2017). Las unidades y subunidades resuelven una buena cantidad de problemas estéticos en la reconstrucción facial, y los diseños de colgajo dependen de los límites de cada unidad (Singh \& Bartlett, 2003). El objetivo de este artículo de revisión bibliográfica fue describir y definir las técnicas más relevantes de colgajos locales faciales y sus algoritmos actuales relacionados con la unidad o subunidad involucrada; sus consideraciones estéticas y la cirugía complementaria.

\section{Anatomía de las unidades estéticas de la cara: implicancias quirúrgicas. El cirujano debe conocer cada detalle de la anatomía de la cara. La cirugía reconstructiva de la cara depende del color de la piel, su textura, la forma, laxitud, líneas de tensión y relaja- ción, líneas de extensión mayor, surcos, pliegues y las arrugas (Burget et al., 1998; Van Leeuwen et al.). Mientras tanto, los vasos y los nervios son estructuras importantes en los diseños de estos colgajos locales. El nervio facial, por su ubicación y recorrido debe te- ner una consideración especial en la planificación o diseño del colgajo. Este nervio emerge a través del foramen estiloides y atraviesa el espesor de la glán- dula parótida, dividiendo la parótida en un lóbulo late- ral (superficial) y en un lóbulo medial (profundo).}

Al principio, el nervio facial se divide en dos ramas: una temporo-cigomática y otra cérvico-facial, la primera continúa con ramos para el buccinador, rama cigomática, temporal y frontal, y el ramo cérvico-facial continúa con un ramo mandibular y cervical $(\mathrm{Ho}, 2015)$. Desde un punto de vista estético, es necesario organizar y dividir esta anatomía compleja en unidades estéticas (Roldán et al., 2007; Singh \& Bartlett; Stein \& Antonyshyn, 2009). El suministro vascular de la cabeza y el cuello está conformado por un gran número de vasos sanguíneos, los cuales permiten que los colgajos locales presenten un menor riesgo de necrosis vascular comparado con otras regiones del cuerpo humano; sin embargo, las arterias principales deben considerarse siempre para lograr un resultado predecible en colgajos que dependen de un suministro sanguíneo axial (Seo et al., 2009; Faris et al., 2015; Rao et al., 2016; Rodríguez-Lorenzo et al., 2016). Estos vasos principales son: arterias faciales, temporales superficiales, supratrocleares, supraorbitarias, infraorbitarias y labiales. La epidermis, dermis, tejido subcutáneo, ligamentos y el tejido adiposo tienen un rol relevante durante la planificación de los colgajos locales para la reconstrucción facial, presentándose en diferentes proporciones y grosores en las distintas unidades y subunidades de la cara. La laxitud depende de estas proporciones, mientras que la mejilla es la zona más laxa de la cara, otras zonas como la frente, el cuero cabelludo y la oreja presentan un tejido mucho más adherido. Lo anterior, permite que la mejilla sea un buen sitio donante para la técnica reconstructiva en base a colgajos locales.

Frente y cuero cabelludo. El cuero cabelludo constituye la zona con mayor área de la cabeza, y al mismo tiempo presenta la piel más gruesa. El cuero cabelludo está compuesto por 5 capas características: piel, que involucra la epidermis y la dermis; el tejido subcutáneo, que contiene el plexo vascular subdérmico; la galea aponeurosis; tejido conectivo laxo y el periostio (Al Shetawi et al., 2017). Esta es un área con baja elasticidad. La frente es un muy buen sitio donante para la reconstrucción facial, proporcionando un excelente color y textura del tejido (Burget et al.; Larrabee \& Moyer, 2017; Luce 2017). Esta unidad facial se divide en tres subunidades: subunidad central, subunidad lateral y subunidad de la ceja. El suministro vascular de la frente incluye el plexo supraorbitario alimentado por las arterias dorsales de la nariz, las arterias supratrocleares y supraorbitarias, y ramas angulares de la arteria facial (Erdogmus \& Govsa, 2007). Este plexo anastomótico está centrado en la región del canto medial y se extiende cefálicamente $7 \mathrm{~mm}$ en promedio hasta el borde orbitario superior. El músculo occipitofrontal, es un sistema muscular emparejado, que incluye el vientre frontal (anterior) y occipital (posterior), conectado en el medio por una fascia aponeurótica (Sokoya et al., 2018). Este músculo tiene un papel importante en el mantenimiento de la posición de la frente.

Párpados. La unidad palpebral se divide en cuatro partes: subunidades del párpado inferior y superior y subunidades del canto lateral y medial. El párpado es una estructura delgada con capacidad de abrirse y 
cerrarse para lubricar y proteger la superficie ocular (Chang et al., 2017). Cualquier interrupción del tejido palpebral puede causar pérdida de la movilidad, flexibilidad o una función mucosa defectuosa. El párpado superior está compuesto por varias capas divididas en dos láminas. La lámina anterior está cubierta por la piel (la más delgada del cuerpo humano) y el músculo orbicular, sin capa adiposa. La lámina posterior está compuesta por el músculo elevador y / o la aponeurosis elevadora, el músculo de Müller y la conjuntiva (Stein \& Antonyshyn; Codner et al., 2010). Inferiormente encontramos un tejido conectivo denso especializado llamado tarso, que actúa dando el soporte al párpado (Chandler \& Gausas, 2005). El suministro de sangre y la inervación provienen de los nervios y arterias supraorbitales y supratrocleares. Estos dos nervios ascienden a la frente proporcionando inervación sensorial a la frente y al vértice del cuero cabelludo.

Nariz. La nariz es una unidad estética compleja compuesta por 9 subunidades: la columela, el dorso, paredes laterales, alas nasales, facetas de partes blandas y la punta nasal. Por otro lado, el esqueleto nasal lo componen los huesos nasales y una serie de cartílagos y ligamentos (Burget \& Menick, 1985; Cox \& Fort, 2017). Los vasos angulares, nasopalatinos y etmoidales anteriores son el principal suministro vascular. Basado en sombras, concavidades y convexidades, los ojos humanos leen estas "piezas" juntas como una nariz completa (Yotsuyanagi et al.).

Mejilla. La mejilla es la región estética facial más grande, y generalmente se divide en 4 subunidades: medial (infraorbitaria), lateral (maseterina o mandibular), cigomática y bucal. El límite de esta región la componen una línea que va desde el canto lateral hasta la raíz del hélix, otra línea que cruza por el surco preauricular, otra por el margen inferior de la mandíbula, y una que pasa por el pliegue mentolabial, el surco nasofacial y la unión entre el párpado y la mejiIla (Pepper \& Baker). Las capas de las mejillas se componen de epidermis, dermis, grasa subcutánea, y el sistema músculo-aponeurótico superficial (SMAS) que se continúa superiormente por la fascia témporoparietal e inferiormente por el platisma (Pepper\& Baker). En general, la piel está más adherida al tejido profundo hacia la zona lateral, y medialmente el tejido presenta mayor movilidad y proporción de grasa. Esto se debe a la presencia de ligamentos que surgen desde cigoma con dirección hacia la mandíbula (Pepper \& Baker). Estos ligamentos se originan del tejido óseo y se unen directamente a la dermis suprayacente. EI suministro de sangre en la región de la mejilla está dado principalmente por la arteria transversa de la cara y las perforantes de la arteria facial, con una contribución menor de la arteria infraorbitaria. La arteria transversa de la cara surge de la arteria temporal superficial pasando por la glándula parótida y luego se dirige superficialmente a la fascia maseterina para luego conectarse a un plexo subdérmico denso que se arboriza ampliamente. Hay una anastomosis importante entre la región labial y las ramas terminales de las arterias nasales. Hay cientos de perforantes musculocutáneas que se conectan directamente a las ramas terminales de la arteria facial. Debido a esto, la necrosis de un colgajo cutáneo tiene una ocurrencia muy baja (Rodríguez-Lorenzo et al.; Al Shetawi et al.).

Labios y mentón. La unidad del labio superior se divide en subunidad del filtrum, subunidades laterales y subunidad mucosa. En esta región se aprecia el músculo orbicular. Este músculo consta de 4 cuadrantes independientes que se entrelazan para dar la impresión de circularidad. El labio es irrigado por la arteria facial a través de las arterias labiales superiores e inferiores. Por otro lado, existe una diversa red de vasos que irrigan el filtrum a través de ramas terminales de la arteria labial superior. Burget \& Menick describieron las subunidades estéticas del labio. Lateralmente, están limitadas por el surco nasolabial, el límite superior lo constituye la base nasal y el límite inferior está dado por el surco mento-labial. Los principales elementos vasculares son los vasos faciales y labiales, y la inervación está dada por ramos bucales del nervio facial, nervios infraorbitarios y mentonianos. El mentón es una unidad estética única que confiere fuerza a la cara que está delimitada superiormente por el surco mentolabial, inferiormente por el borde inferior del mentón y lateralmente por el pliegue mento-labial. Las capas del mentón son la piel (la más gruesa de la cara), el tejido subcutáneo y los músculos del mentón. El suministro de sangre del mentón proviene principalmente de la arteria mentoniana, la arteria labiomental y la rama terminal de la arteria submental (Larrabee \& Moyer).

\section{Colgajos locales en reconstrucción facial, proto- colos según unidades estéticas}

Técnicas frecuentes y puntos clave. La reconstrucción de la cara luego de resecciones de piel o defectos de tejidos blandos debe ser planeada por el cirujano teniendo consideraciones especiales. Dependiendo del tamaño y lugar existen diferentes diseños de colgajos locales. El sitio donante debe permitir suficientes tejidos para corregir el defecto, considerando 
el color, la textura, elasticidad y laxitud de al que reemplaza. Las líneas de relajo de la piel permiten adecuados resultados estéticos cuando son considerados dentro de la reconstrucción, sin embargo, no son el único factor. Los límites de unidades y subunidades permiten un cierre cosmético cuando las incisiones son realizadas dentro de estos límites, principalmente en las líneas periféricas de estas unidades. Triángulo de Burow, plastias en "M", plastias en " $Z$ " y cierres en forma de "S" (en defectos largos), constituyen buenos recursos para reducir o mimetizar cicatrices luego de cirugías reconstructivas, ángulos en $30^{\circ}$ pueden ayudar a logar mejores resultados reduciendo la tensión de los tejidos al momento del cierre. Disminuir la tensión del tejido subcutáneo es fundamental para aliviar el cierre cutáneo, suturas continuas, intradérmicas o discontinuas ofrecen buenos resultados. Grosores de suturas 5-0,6-0,7-0 son excelentes opciones para lograr buenos resultados. En paralelo, los procedimien-

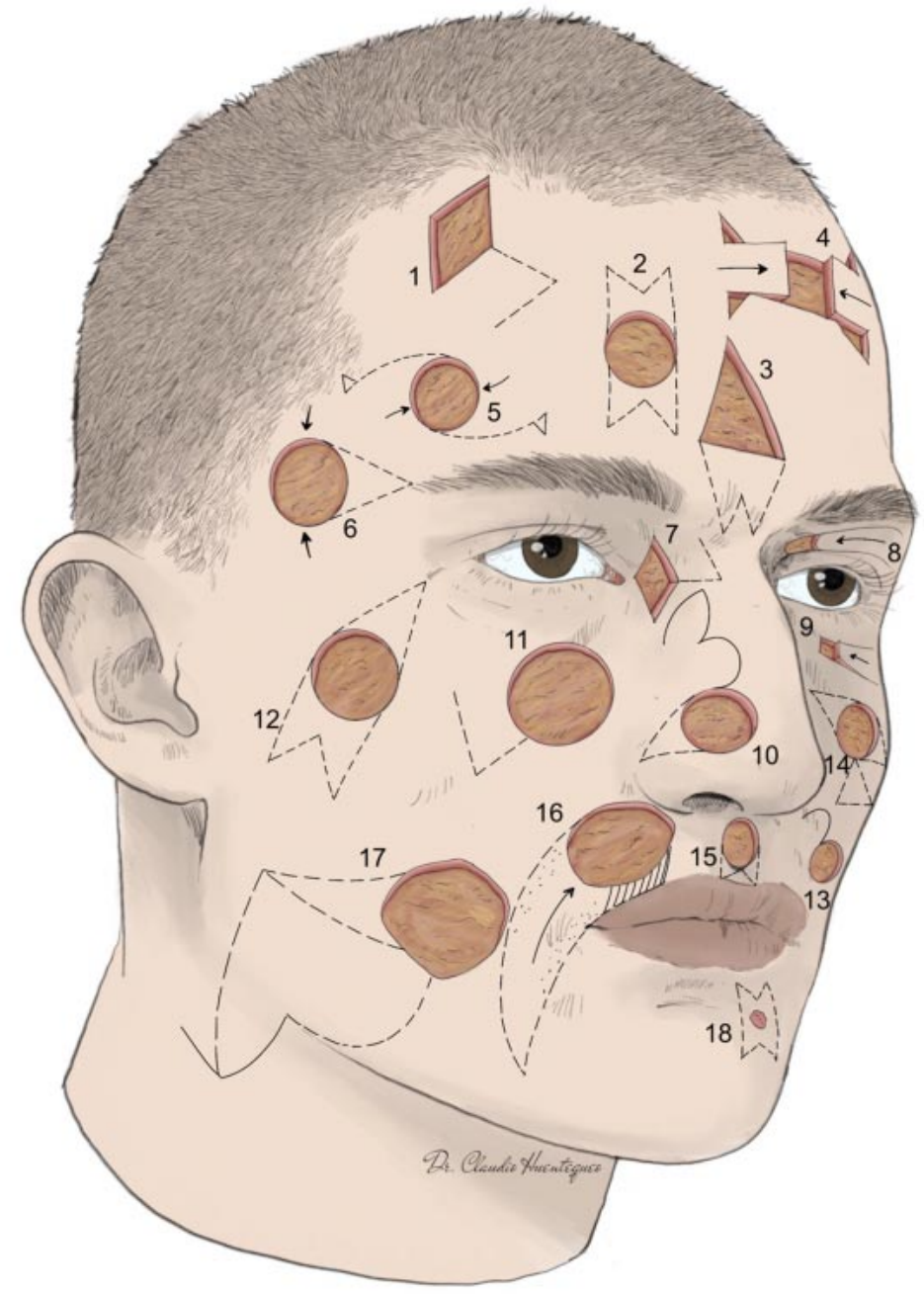

Fig. 1 Esquema de colgajos locales de la cara por unidad estética. tos cosméticos juegan un rol importante para disminuir o esconder defectos luego de cirugías reconstructivas. Las expansiones de tejidos, blefaroplastias, cantoplastías, ritidectomías, implantes de foliculares, comisuroplastías, levantamiento de cejas, rellenos y el uso de toxina botulínica (en caso de paresias o hipoparesias), abrasión dérmica o incluso tatuajes deben ser considerados.

Unidad estética de la frente. La reconstrucción de la frente debe considerar importantes objetivos. Evitar daño a estructuras nerviosas, mantener y continuar líneas de cabello y cejas, cicatrices deben situarse en estas líneas o sus márgenes. Si existe la posibilidad deben crearse cicatrices horizontales (con excepción de la zona media de la región frontal), y evitar incisiones diagonales. El colgajo de avance y bilateral son los más usados en esta región, incluyendo A-T, O-T, $\mathrm{O}-\mathrm{Z}$, plastias en "H" o en "T" dependiendo del lugar y el requerimiento (Fig. 1). En la zona media de la frente cierres verticales son indicados, plastias en "M" o "W" son realizadas frecuentemente para evitar defectos cutáneos (Fig. 1). Ocasionalmente para prevenir defectos en la ceja, una expansión de tejidos es usualmente ejecutada. Los defectos de mayor tamaño pueden ser reparados mediante colgajos rotados bilaterales y efectuando un cierre vertical, escondiendo la cicatriz resultante en el cuero cabelludo. Cierres horizontales de los defectos paramedianos están indicados, sin embargo, puede afectar directamente la zona de la ceja, levantándola. Una alternativa para evitar esta complicación es suturar la piel al periostio del arco supraorbitario. Colgajos de avance horizontal y bilaterales son indicados, usualmente el tamaño del colgajo es calculado en una proporción de 4:1 (tamaño del defecto), aumentado en el tejido subcutáneo, colgajos laterales deben ser más largos que los medianos debido a su mayor laxitud y elasticidad (Seitz \& Gottlieb, 2009). Defectos laterales menores a $1,5 \mathrm{~cm}$ pueden ser reparados principalmente colgajos de avance, de transposición o rotados, una buena elección son los colgajos "A-T" o "OZ" (Fig. 1). Se debe tener cuidado con la disección del tejido subcutáneo en relación con las ramas temporales del nervio facial. Los defectos más grandes pueden tratarse con colgajos rotados de cuero cabelludo, combinados con otros colgajos locales. Otra opción para defectos más extensos es el uso de expansora de tejidos (O'Reilly et al., 2012). 
Unidad estética de la peri-órbita y párpados. Lesiones de los párpados que no comprometen el margen de estos pueden ser tratadas mediante colgajos "romboidales", avances "V-Y", de transposición y bipediculados (Fig. 1). Defectos de los márgenes por debajo de $1 / 3$ se puede tratar mediante cierre primario, facilitándolos con cantotomías y cantolisis. Entre 1/3 y 12 un colgajo de rotación y avance como el de "Tenzel" está indicado, una incisión semicircular extendida desde el canto externo $20 \mathrm{~mm}$ hasta la línea lateral de la ceja. Los colgajos musculocutáneos se realizan en combinación con cantotomías y cantolisis; posteriormente un avance y cierre meticuloso es necesario. En el párpado inferior, colgajos de mejillas son excelentes opciones para defectos moderados, pero el colgajo de Tenzel entrega mejores resultados estéticos (Fig. 2). Defectos mayores al $70 \%$ en el párpado inferior pueden ser tratados mediante colgajos de "Hughes" (Chandler \& Gausas; Codner et al.), este colgajo "tarso-conjuntival" se obtiene desde el párpado superior 3-4 $\mathrm{mm}$ desde el margen y avanza hasta el párpado inferior en su parte posterior. La reparación de la piel puede realizarse mediante colgajos de avance, colgajos de piel de espesor total o colgajos locales (Fig. 2). Durante este momento el paciente no puede ver a través de este ojo, debido al pedículo, luego de 7 a 45 días se retira el pedículo. Defectos mayores a $50 \%$ del párpado superior, incluido el margen, se pueden tratar mediante el colgajo de "CutlerBeard", de espesor completo (piel y tejido conectivo), éste es obtenido desde el párpado inferior, mediante una incisión anterior sobre la piel bajo el tarso y luego sobre la conjuntiva del párpado inferior, por donde se desplaza el colgajo de espesor total a través del abordaje transconjuntival para luego suturarlo al párpado superior (Fig. 2). En una segunda etapa 6-8 semanas luego del primer procedimiento, se elimina el pedículo del
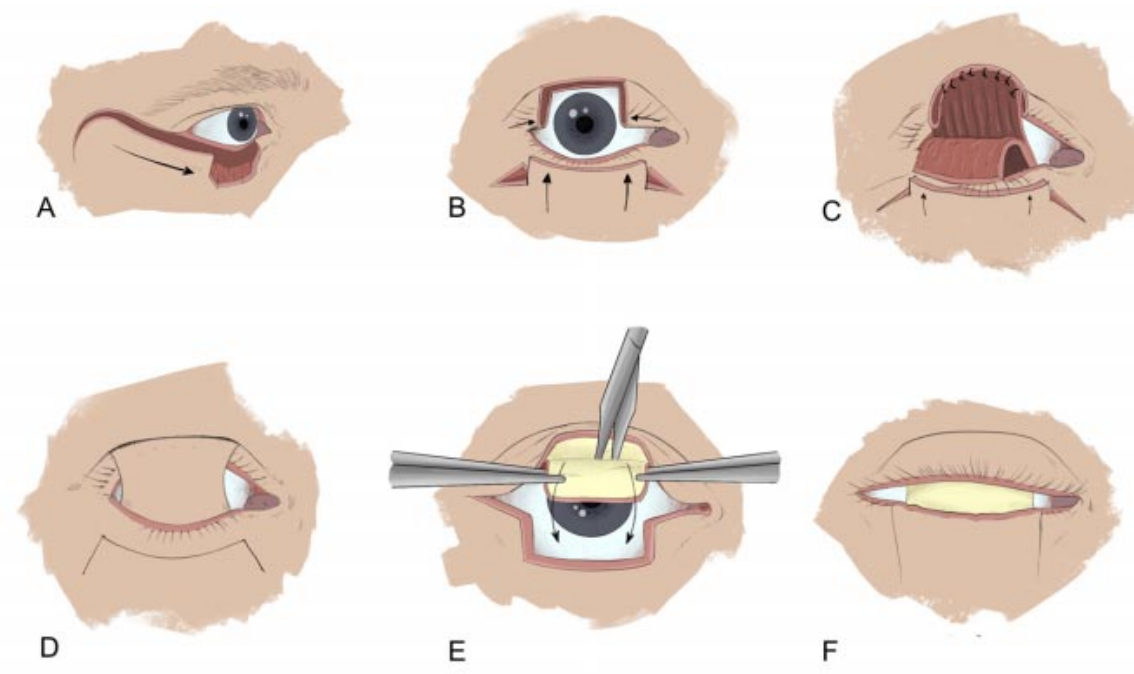

colgajo. Para mejorar la estabilidad en la reconstrucción superior luego de un colgajo de "Cutler-beard", cartílago, injerto de paladar $u$ otros métodos pueden ser utilizados. Defectos del canto medial sin compromiso de los márgenes o sólo defectos de piel pueden ser reparados mediante colgajos de transposición glabelar o de transposición (Fig. 3). En los defectos más grandes, el tendón del canto medial y los tejidos blandos deben sujetarse al hueso para estabilizar la posición, se debe lograr una suspensión superior y posterior hacia el hueso (cercano a la cresta lagrimal) (Codner et al.). Mientras la reconstrucción del canto lateral puede tratarse mediante colgajos de avance semicirculares y/o colgajos de avance periósticos. El tendón cantal debe fijarse al periostio o al borde orbitario lateral $2 \mathrm{~mm}$ por encima de la línea horizontal del canto medial (Codner et al.). El colgajo frontal es otra opción para reparar defectos más grandes en los párpados superior e inferior en la región periorbitaria (Price et al., 2004).

Unidad estética de la mejilla. Para la reconstrucción de la mejilla esta debe ser dividida por zonas o subunidades a modo de elegir la técnica más adecuada. Esta amplia región y la ausencia de bordes y líneas representan un gran desafío cosmético. El pliegue melolabial es la primera elección para camuflar una incisión, lo sigue el surco naso-labial en aquellos casos que no involucren la pared lateral nasal. No obstante, cuando el defecto incluye la pared nasal las líneas del pliegue naso-labial permiten aceptables resultados estéticos con el colgajo de avance (Fig. 4). Defectos moderados pueden ser tratados por cierre primario en ausencia de tensión, en párpados o labios las alternativas son colgajos rotados, en "isla", colgajos de avance, rotados y de avance de mejilla o cérvico-faciales, romboidales (Limberg) o de transposición (Fig. 1).

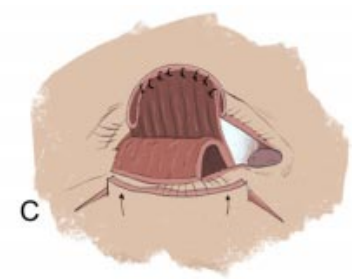

Fig. 2. Esquema: (A) Colgajo de Tenzel; (B) CuttlerBeard: abordaje y resección del defecto; (C) Colgajo Cutler-beard de espesor total de avance; (D) Cierre del colgajo Cuttler-Beard; (E) Disección del colgajo de Hughes; (F) Cierre del colgajo de Hughes y su pedículo. 
HUENTEQUEO, C. M.; SISO, S. C.; UNIBAZO, A. Z.; PINO, D. D.; ALISTER, J. P. H.; MAYER, C. O. \& OLATE, S. Colgajos locales en reconstrucción facial. Alternativas de tratamiento. Int. J. Odontostomat., 15(2):538-550, 2021.
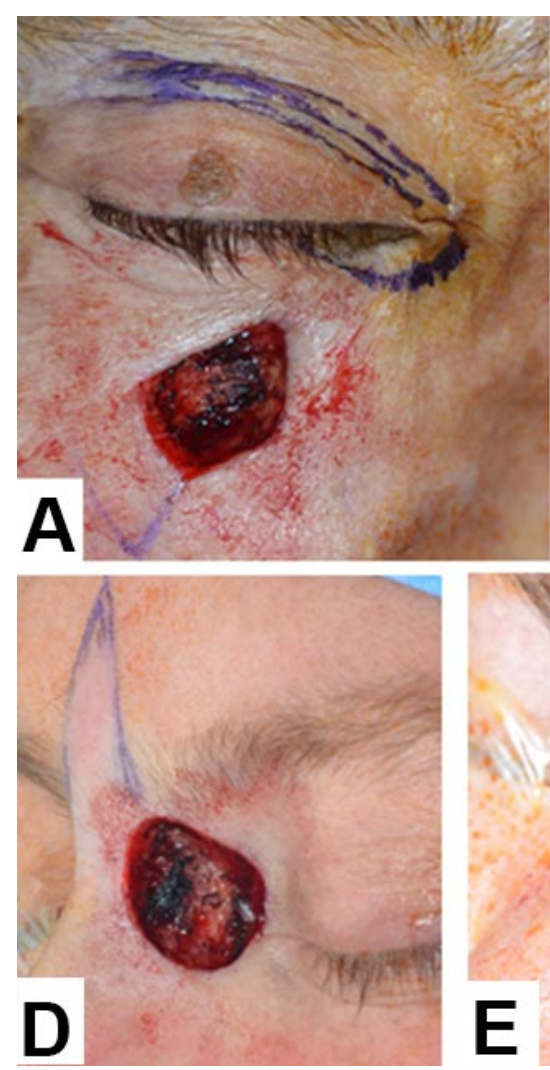
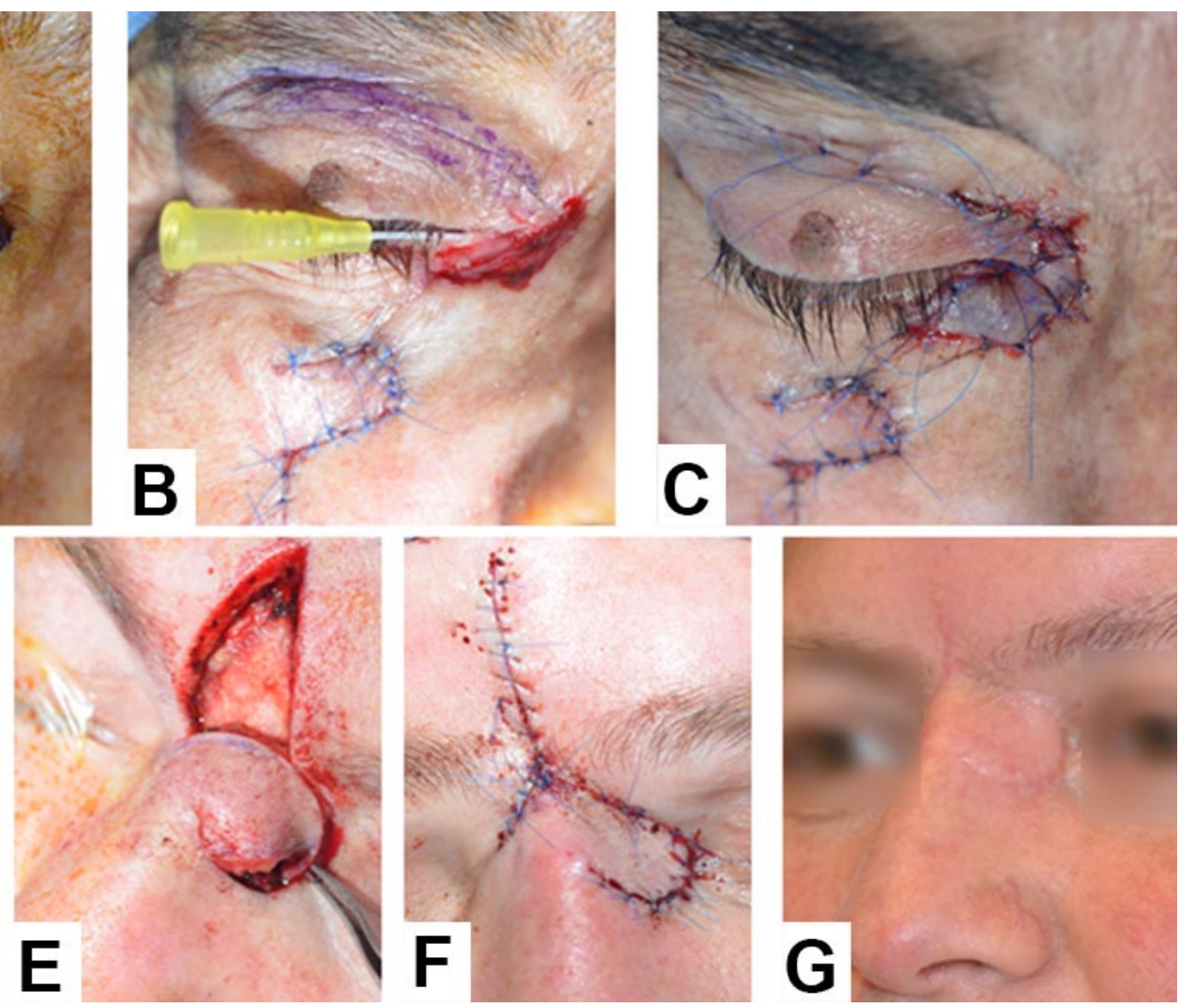

Fig. 3. Reconstrucción de párpado: (A) colgajo de transposición romboidal (de Limberg); (B) lesión y protección del conducto lacrimal, (C) cierre; (D) diseño del colgajo de glabela y defecto nasal y de párpado inferior; (E) colgajo de rotación; $(F)$ cierre, $(\mathrm{G})$ Control a los 3 meses.
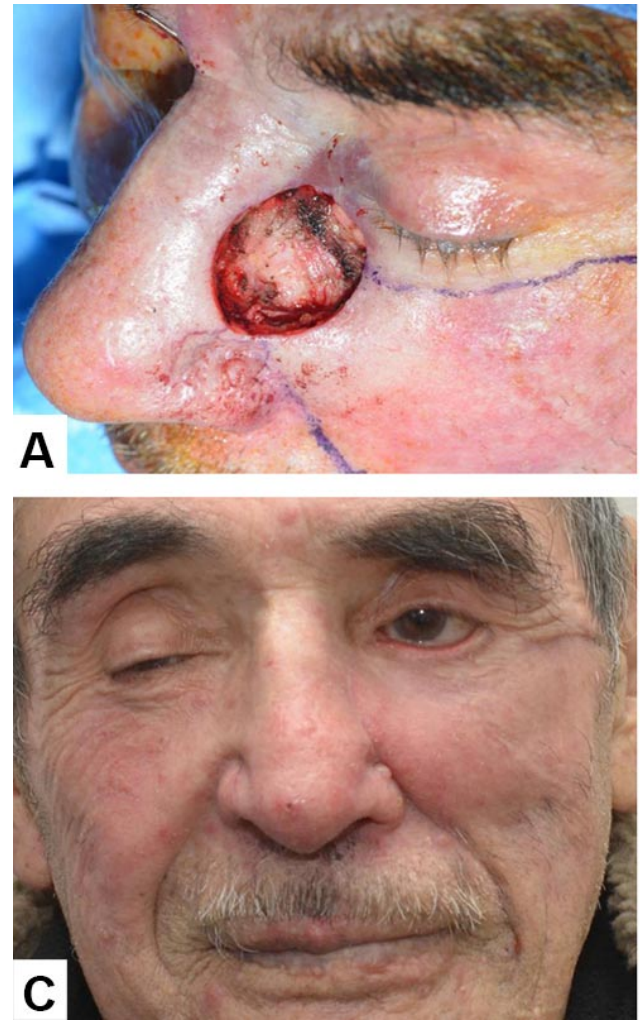
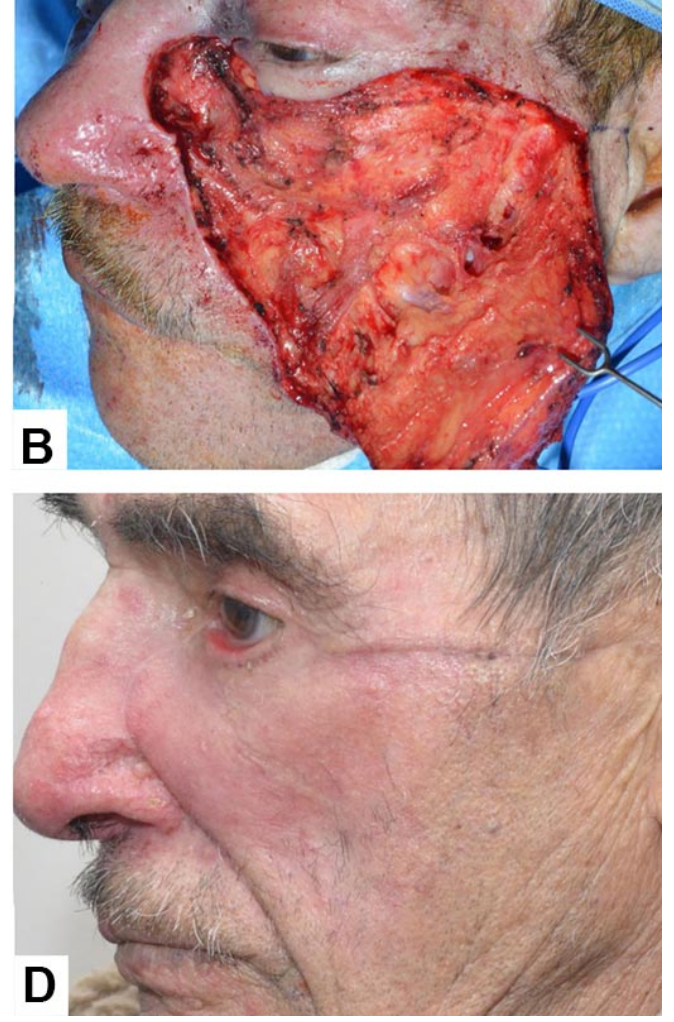

Fig. 4 (A). defecto nasal y de mejilla; (B) colgajo de rotación y avance de mejilla elevado; (C) control a los 3 meses, la vista frontal muestra un resultado estético favorable, pero un ectropión como secuela; (D). control a los 3 meses vista lateral. 
El colgajo de avance y rotación (Mustarde) de la mejilla corresponde a una alternativa versátil en la reconstrucción de la zona medial de la mejilla (Fig. 4). Para defectos moderados la incisión debe seguir los márgenes de unidades estéticas, con una base inferomedial-medial, comenzando en la zona medial del defecto y luego descendiendo por el surco melolabial, luego se extiende horizontalmente a través de reborde orbitario y finalmente curvándose suavemente en el cuerpo del cigomático justo sobre el canto lateral. Para defectos de mayor tamaño, se puede extender hacia abajo mediante un colgajo cérvico-facial (Al Shetawi et al.), a través de la línea temporal del cuero cabelludo, hacia abajo por el margen lateral de la unidad estética, a través del pliegue auricular, extendiéndose hacia posterior alrededor del lóbulo de la oreja, a lo largo de la línea lateral del pelo, descendiendo en el pliegue cervical transverso hacia una dirección anterior. El colgajo debe terminar en el cuello o bajo la clavícula o la región pectoral. Colgajos más grandes deben considerar disección bajo el SMAS para asegurar la irrigación sanguínea (Wo et al.).

Para evitar la retracción del párpado inferior o ectropión (Fig. 4), la incisión horizontal debe pasar sobre el canto lateral y suturar desde el colgajo hacia el periostio. Algunos autores utilizan el pliegue subtarsal para evitar esta retracción, sin embargo a veces, puede dar lugar a un linfedema en esta zona (Wo et al.).

Para los defectos laterales se puede aprovechar la laxitud de esta zona, el pliegue preauricular permite un buen cierre vertical en pequeños o medianos defectos de esta zona, mientras que la laxitud en las zonas cervicales y laterales permite colgajos de avance hacia una dirección superior con ayuda del "Triángulo de Burrow", bajo el lóbulo de la oreja en caso de ser requerido (Wo et al.). Colgajos de transposición retroauricular pueden ser útiles en algunos defectos en esta zona, a través del surco retroauricular y línea lateral del pelo. El colgajo bilobulado es útil en algunos defectos medianos cercanos a la zona bucal (Fig. 1). El colgajo cérvico-facial queda reservado para defectos de mayor tamaño (más de $3 \mathrm{~cm}$ ) (Al Shetawi et al.).

En pequeños defectos de la zona cigomática (menor a $1 \mathrm{~cm}$ ), puede ser utilizado colgajos romboidales en paralelo a líneas de mínima tensión o colgajos de avance (Fig. 1), mientras que colgajos de avance y rotación de la mejilla puede ser útiles en defectos de mayor tamaño.
Unidad estética nasal. Los principios de colgajos en reconstrucción nasal están bien establecidos por cada subunidad de la nariz. Defectos que involucran más de $50 \%$ de la subunidad deberían ser tratados como un defecto completo de la misma subunidad. Se han descrito varias opciones para la reconstrucción nasal incluyendo colgajos rotados (Fig. 6), colgajos frontales (Menick, 2004) o bilobulados (Fig. 1 y 6), uno de los más versátiles y usado (Feintisch et al., 2016). Otro colgajo útil es el de mejilla y de naso-labial de avance. Adicionalmente, varias técnicas y protocolos son usados en diferentes colgajos en combinación con injertos de cartílago y piel (Yoon et al., 2006). El colgajo frontal es realizado $2 \mathrm{~cm}$ lateral a la línea mediana facial sobre la arteria supratroclear (Menick, 2002), la base debe ser menor a $1,5 \mathrm{~cm}$, debido al ángulo de transposición y la incisión debe realizarse sobre las líneas de corrugador. Una vez alcanzada la capa subgaleal, inmediatamente se transpone y se realiza el adelgazamiento dependiendo del tipo de defecto (Hsiao et al., 2017) (Fig. 5). Dos o tres semanas luego se debe evaluar la neovascularización distal, pinchando la parte proximal del colgajo. En los casos en que no se utilizará un colgajo frontal, colgajos unilaterales o bilaterales de avance de mejilla son una excelente opción para reemplazar el dorso y zonas laterales luego de resecciones, ocasionalmente con menores resultados estéticos en comparación al colgajo frontal (Cox \& Fort ). Una especial consideración es que se debe extender el colgajo al menos a nivel de la línea cantal lateral. En la unión del ala con la mejilla el colgajo puede cortarse una o dos veces. Frecuentemente una segunda cirugía es necesaria para mejorar los resultados estéticos, principalmente los surcos y los márgenes del colgajo. Adicionalmente, colgajos unilaterales o bilaterales interpolados del pliegue melolabial pueden ser usados para la reconstrucción del ala y "tip" nasal (Fig. 5), el colgajo es extendido bajo la comisura labial sobre el surco melo-labial, alcanzando el plano subcutáneo mediante disección roma, luego se logra al avance del colgajo y la reparación del defecto. Tres semanas después el pedículo es cortado.

Unidad estética del labio. Defectos menores a $1 \mathrm{~cm}$ deben ser reparados mediante cierre primario. La piel o defectos superficiales pueden ser tratados mediante colgajo de avance, transposición o rotados (Fig. 1). Defectos del bermellón podrían curarse mediante colgajos mucosos de avance, colgajos musculomucosos que incluyan la arteria facial (Ayad et al., 2004; Ayad \& Xie , 2015) o colgajos de lengua. Me- 

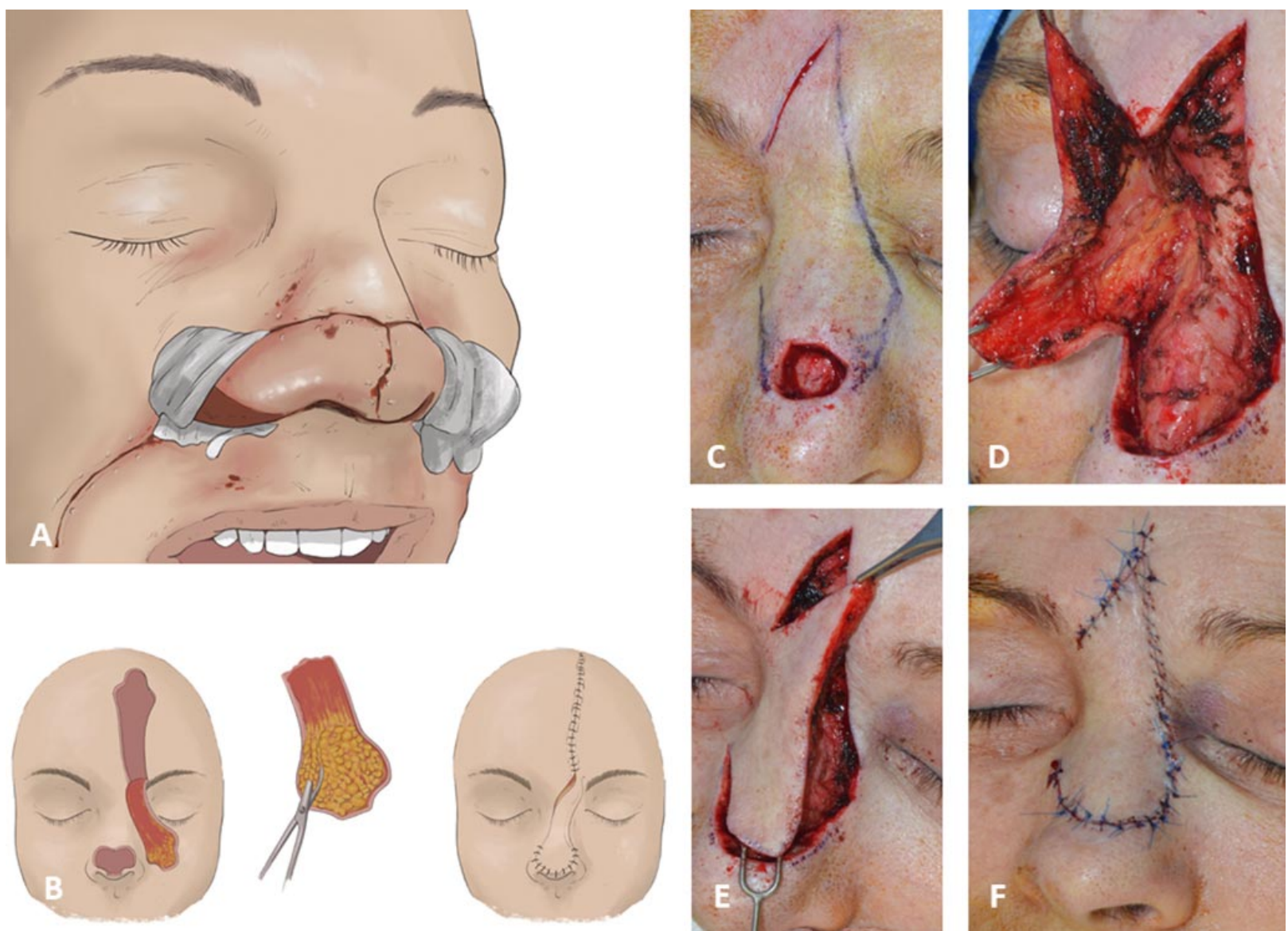

Fig. 5. (A) Esquema de colgajo melolabial bilateral para defecto nasal; (B) Esquema de colgajo frontal para reconstrucción nasal; $(C)$ diseño de colgajo de rotación y avance de glabela y defecto nasal; (D) colgajo Elevado; (E) Rotación del colgajo (F) cierre del colgajo.
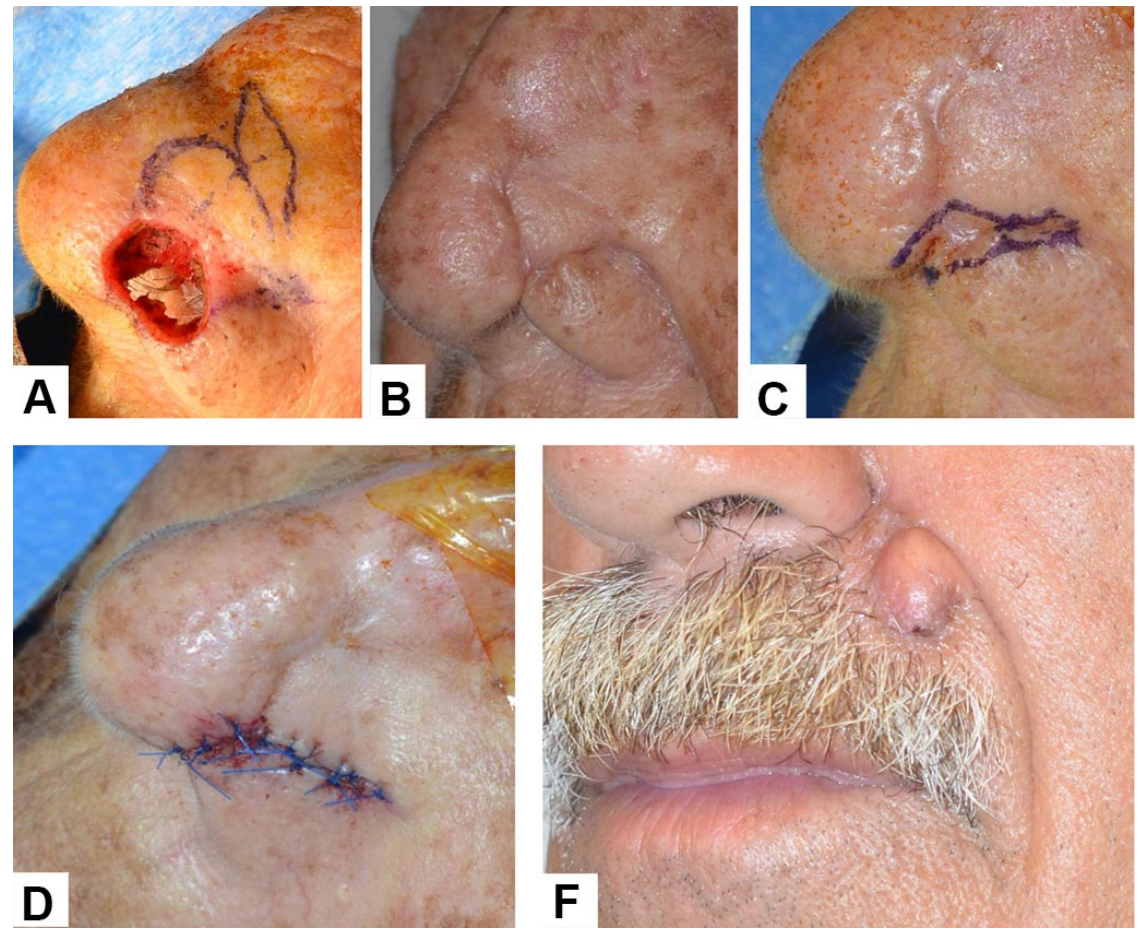

Fig. 6. (A) Diseño de colgajo Bilobulado nasal y defecto alar(B) control 1 mes, defecto después de la reconstrucción, (C) resección y plastía de la cicatriz, (D) nuevo cierre, (E) Defecto Trap-Door después de colgajo de rotación. 

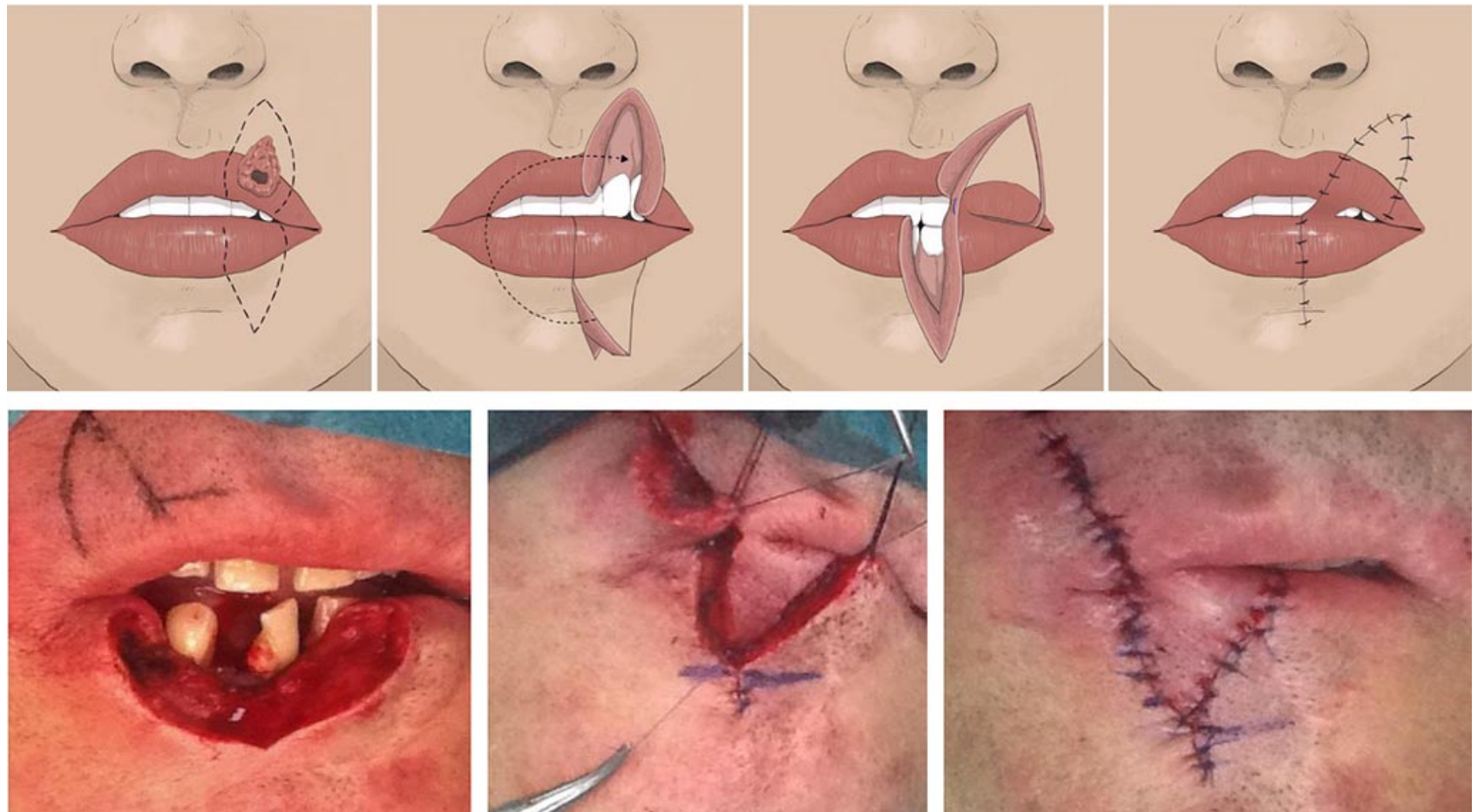

Fig. 7. Superior: Esquema de colgajo de Abbé para labio superior; Inferior: Colgajo de Abbé para labio inferior.

nos del $30 \%$ podría ser tratado con mediante un cierre primario de espesor completo y en ocasiones combinado con plastias en forma de "A","M" o "W". La reconstrucción del filtrum conlleva buenos resultados usando colgajos obtenido desde el labio inferior, considerando que si el defecto es mayor a $50 \%$ de esta subunidad debería ser reemplazado completamente (Burget et al.; Pepper \& Baker; Luce). La zona medial los defectos laterales de esta subunidad que sean menores a $1,5 \mathrm{~cm}$, un avance lateral podría ser una opción apropiada (Fig. 1), manteniendo una correcta longitud vertical del colgajo de avance de la mejilla al labio, puede ser logrado mediante un diseño cuadrangular y un triángulo de "Burrow" en la zona perialar. Si el defecto es mayor a $1,5 \mathrm{~cm}$ un colgajo rectangular, de Abbé o Estandler (en caso de defectos de comisura), están indicados (Fig. 7). En aquellos defectos de la mitad del labio superior, la unidad lateral completa, labio superior y una parte de la mejilla, un colgajo nasolabial está indicado. Cuando diferentes unidades y subunidades del labio superior están comprometidas, una combinación de estos colgajos locales está indicado, otras alternativas menos frecuentes, son colgajos de avance de "Karapandzic" (explicado luego para en labio inferior), colgajo de Gillies o Mc Gregor (Burget et al.; Larrabee \& Moyer; Luce).
La reconstrucción del labio inferior depende del tamaño y de la piel. Los defectos de un tercio a $50 \%$ pueden ser tratados mediante el colgajo de Abbé o Estandler, este último en defectos laterales (Fig. 7). Un defecto de más de un tercio hasta dos tercios, pueden ser reparados con colgajos de "Karapandzic", este colgajo de avance cutáneo y subcutáneo depende de las arterias labiales, la técnica combina dos incisiones semicirculares que comienzan en la zona de la lesión, rodean la comisura en paralelo o sobre el pliegue nasolabial (Ye et al., 2014), obteniendo la suficiente longitud para cerrar el defecto (Fig. 8). De ser necesario reparar defectos mayores a dos tercios, técnica de "Webster-Fries" (colgajo de Bernard-Webster modificado) es una excelente alternativa, la que consiste en un colgajo de avance cutáneo y subcutáneo desde la mejilla donde cuidadosamente se disecan los planos musculares evitando dañar los ramos terminales del $\mathrm{N}$. facial para unirlos en el cierre con el plano contralateral y luego los planos mucosos los cuales serán cerrados mediante un colgajo de avance V-Y. A través de la escisión en piel de cuatro triángulos de Burow en las líneas estéticas laterales se facilita el avance del colgajo, en conjunto con una línea en « $\mathrm{V} »$ o cuadrangular sobre el mentón. En un segundo tiempo se reconstruye el bermellón con un colgajo de mucosa de avance o un injerto de mucosa (Roldán et al.) (Fig. 8). 

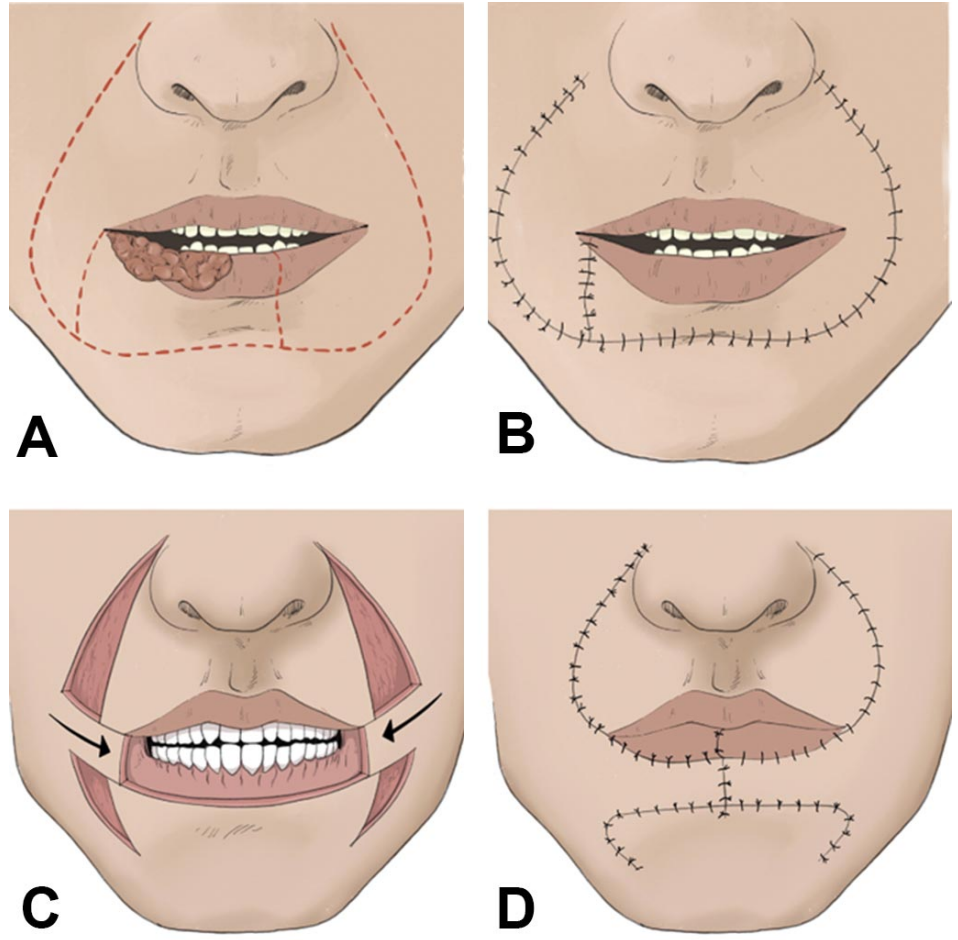

Fig. 8. Esquema: (A) Diseño colgajo Karapandzic y defecto de labio inferior; (B) Cierre de colgajo de Karapandzic; (C) Colgajo Webster Fries; (D) Cierre del colgajo de Webster Fries.

Complicaciones y cirugía complementaria. Varias técnicas y procedimiento en la reparación de defectos han sido descritos para obtener mejores resultados estéticos tras reconstrucción con colgajos locales. Una de las principales complicaciones es la diferencia en la textura y color de la piel; dehiscencias, necrosis, contracturas cicatrizales hipertróficas o atróficas, microstomias, síndrome de "trap-door" (Koranda \& Webster, 1985) (Fig. 6), blefaroptosis, blefarochalasis, ectropión (Fig. 4), estos defectos del párpado pueden tratados mediante técnicas de blefaroplastía y cantoplastía.

Revisión de la cicatriz. El tratamiento de las cicatrices no estéticas o disfuncionales pueden lograrse mediante diversos métodos, dentro de los más populares y versátiles son las "zeta-plastías", debido a que tiene varias indicaciones, interrumpe las líneas cicatrizales, cicatrices no estéticas, cambios en la orientación de la cicatriz para lograr alineamiento de las líneas de relajo de la piel (Hudson, 2000). La angulación del colgajo debe permitir liberar liberar la contracción cicatrizal, dependiendo del ángulo del colgajo: $60^{\circ}, 45^{\circ}$ o $30^{\circ}$, liberan aproximadamente el 75 $\%, 50 \%$ o $25 \%$ respectivamente, y cambian la direc- ción de la cicatriz en $90^{\circ}, 60^{\circ}$ y $45^{\circ}$ respectivamente. Mientras que las plastías en "W" pueden ayudar a interrumpir las líneas de la cicatriz para lograr paralelizar a las líneas de relajo de la piel (Hudson). Otra opción es la interrupción de la línea geométrica, esto causa una línea aleatoria que logra un efecto de camuflaje frente a la visión humana. El ácido hialurónico es una opción para mimetizar la contracción por la cicatriz, mientras que la dermo-abrasión puede lograr mejorar la textura y el color.

Comisuroplastías. Varios métodos han sido descritos, Kazanjian y Converse fueron uno de los primeros autores en describir este método. La técnica de comisuroplastía es usada en casos de microstomía luego de reconstrucciones de labio (Jhamb \& Mohanty, 2010). Frecuentemente es necesaria en un segundo tiempo luego de la cirugía. Actualmente consiste en una incisión horizontal en la comisura afectada, luego se avanza la mucosa del labio de cada lado de la incisión para crear un nuevo bermellón, además se puede extirpar un triángulo cutáneo y subcutáneo para mejorar los resultados estéticos (Berlet et al., 1993). Otra excelente opción es extirpar un triángulo cutáneo y subcutáneo, luego se hace una incisión en el bermellón y en el musculo orbicular, el pedículo resultante se avanzado hacia la nueva comisura, finalmente un colgajo de avance de la mucosa para cubrir el músculo, creando un nuevo labio (Berlet et al.). (Fig. 9).

Expasión tisular. En aquellos casos donde falte tejido para cubrir un defecto, la expansión de tejidos es una excelente opción. La técnica consiste en insertar un expansor bajo la capa subcutánea en la cara o el cuello, o incluso bajo el platisma, mientras que en el cuero cabelludo debe insertarse en la capa subgaleal. La incisión debe hacerse entre el colgajo y la zona de expansión, sin embargo, debe elegirse un lugar con una adecuada irrigación sanguínea. El puerto debe colocarse a través del mismo abordaje teniendo especial cuidado con no obstruir este dispositivo cuando se inicie la expansión. Suturas en diferentes planos deben ser realizadas para asegurar un cierre correcto. En la región retroauricular deben evitarse la inserción de estos expansores, mientras que las regiones más usadas son el cuero cabelludo, el cueIlo, las mejillas y la frente (O'Reilly et al., 2012). 


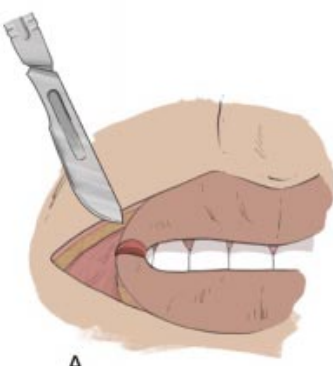

A
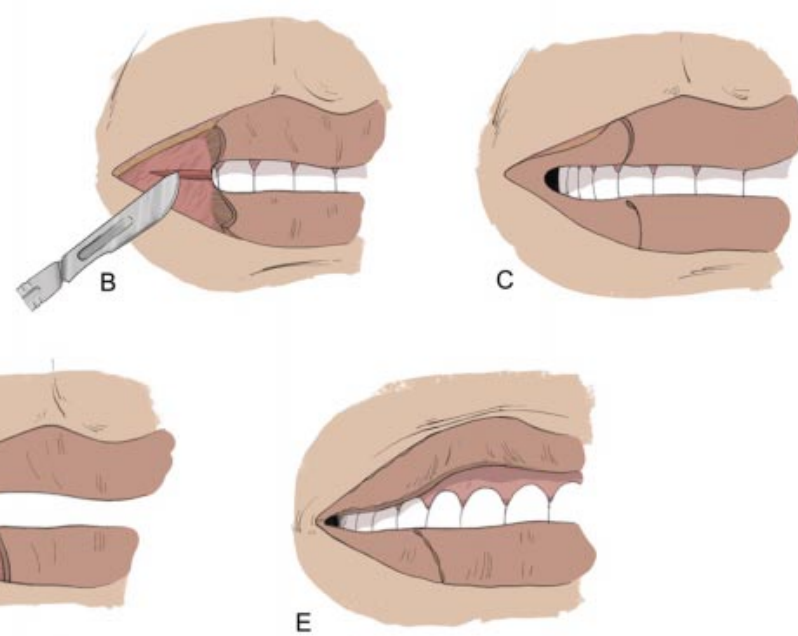

Fig. 9. Esquema de comisuroplastía: (A) Resección triangular en piel e incisión en labio; (B) Incisión horizontal en el M. Orbicular; (C) colgajo de avance de mucosa y nueva comisura; (D)Técnica de comisuroplastía alternativa: resección de un triángulo de piel, corte del bermellón inferior, incisión horizontal del $m$. Orbicular y rotación y colgajo de rotación y avance de bermellón; (E) colgajo de avance inferior de mucosa y nueva comisura.

\section{DISCUSIÓN}

La cara es un componente estético determinante; en conjunto con su compleja anatomía exige al cirujano técnicas meticulosas para lograr un resultado reconstructivo apropiado. Los resultados estéticos requieren diferentes técnicas y protocolos según la zona, el tamaño, el color, la edad y otros parámetros. Los colgajos locales en la reconstrucción facial evidencian excelentes resultados para la mayoría de los defectos tisulares en la cara (Roldán et al.; Van Leeuwen et al.). Existe una amplia cantidad de colgajos locales como se muestra en la Tabla I. Durante los años, el concepto de las unidades y subunidades estéticas faciales se han convertido en una parte relevante para tener en cuenta y así obtener resultados más estéticos. El avance de la tecnología y la cirugía como la microcirugía o colgajos regionales son una buena opción en la reconstrucción facial, pero los colgajos locales ocupan el primer lugar en este tipo de reconstrucción evitando una mayor morbilidad con resultados cosméticos respetables. Los algoritmos y las técnicas de colgajos locales en la reconstrucción facial están bien establecidos, existiendo una buena cantidad de opciones de cirugías complementarias para otorgar resultados más estéticos.
HUENTEQUEO, C. M.; SISO, S. C.; UNIBAZO, A. Z.; PINO, D. D.; ALISTER, J. P. H.; MAYER, C. O. \& OLATE, S. Local flaps in facial reconstruction. Treatment alternatives. Int. J. Odontostomat., 15(2):538-550, 2021.

ABSTRACT: Skin face defects are frequently sequels of basal cell carcinomas, squamous cell carcinomas, melanomas, and large benign tumors or soft tissue trauma. Aesthetics units and subunits of the face, texture, color, and other parameters must be considered in the local flaps reconstructive planning. This review article aims to describe and define the most relevant techniques of facial local flaps in facial reconstruction and their current algorithms, regarding the unit or subunit, involve, their aesthetics considerations and complementary surgery. The aesthetics units and subunits of the face are divided into forehead, eyelids, cheek, nasal, lips, and chin. There are several well-known concepts and flaps used in these proceedings as rotation, island, advancement, and transposition flaps, and they are the basis for facial local flaps; The most relevant are: forehead flap, cheek advancement, and rotate flap; rhomboid, cervicofacial and bilobed flap, nasolabial flaps. The flap election depends on the zone and unit involve; it is important to choose the lines, sulcus, and borders of these units when is possible to enhance these aesthetics outcomes. These concerning improve the aesthetics outcomes and reduce the aesthetics sequels. Complementary surgery and aesthetics proceedings may accomplish a good camouflage of some aesthetics complications or sequels.

KEY WORDS: Local flaps, local flaps in facial reconstruction, facial aesthetics units, facial reconstructive surgery, facial skin cancer. 
HUENTEQUEO, C. M.; SISO, S. C.; UNIBAZO, A. Z.; PINO, D. D.; ALISTER, J. P. H.; MAYER, C. O. \& OLATE, S. Colgajos locales en reconstrucción facial. Alternativas de tratamiento. Int. J. Odontostomat., 15(2):538-550, 2021.

Tabla I. Protocolos y algoritmos de los colgajos locales en reconstrucción facial basado en las unidades estéticas, complicaciones más comunes, cirugía complementaria y/o puntos claves. NEM: no envuelve el margen palpebral, EM: envuelve el margen palpebral.

\begin{tabular}{|c|c|c|c|c|c|}
\hline Unid ad Estética & Ub icación & $\begin{array}{l}\text { Colgajo local: } \\
\text { defecto moderado }\end{array}$ & Colgajolocal: defecto extenso & $\begin{array}{l}\text { Compli caciones } \\
\text { comunes }\end{array}$ & $\begin{array}{l}\text {-Puntos clave } \\
\text {-Cirugía complemen-taria }\end{array}$ \\
\hline \multirow[t]{2}{*}{ Frente } & $\begin{array}{l}\text { Lateral y parame- } \\
\text { diano }\end{array}$ & $\begin{array}{l}\text { De avance, romboidal, O-T, O- } \\
\mathrm{Z} \text {, A-plastia. }\end{array}$ & Rotacionalesde Scalp, avance bilateral de frente & $\begin{array}{l}\text { Daño del ramo frontal } \\
\text { del N. Facial }\end{array}$ & $\begin{array}{l}\text { Expansor tisular, elevación de } \\
\text { ceja o liberación de la tensión de } \\
\text { ceja }\end{array}$ \\
\hline & media & $\begin{array}{l}\text { De avance, M-plastia or W- } \\
\text { plastia y cierre primario vertical }\end{array}$ & $\begin{array}{l}\text { Avance bilateral, W-plastia o M-plastia máscierre } \\
\text { primario }\end{array}$ & Daño N supraorbitario & $\begin{array}{l}\text { Expansor tisular, elevación de } \\
\text { ceja o liberación de la tensión de } \\
\text { ceja }\end{array}$ \\
\hline \multirow[t]{3}{*}{$\begin{array}{l}\text { Párpado } \\
\text { su perior }\end{array}$} & media & $\begin{array}{l}\text { NEM: romboidal, avance V-Y, } \\
\text { avance horizont al palpebral } \\
\text { EM: cierre primario }\end{array}$ & $\begin{array}{l}\text { EM o defecto extenso: Tenzel }(1 / 3 \text { a } 2 / 3 \text { del } \\
\text { párpado); Cutler-Beard }(>50 \%)\end{array}$ & $\begin{array}{l}\text { Ptosis palpebral, } \\
\text { lagoftalmo }\end{array}$ & $\begin{array}{l}\text { Cuttler-Beard: injertode paladar } \\
\text { o cartílago para estabilizar el } \\
\text { párpado }\end{array}$ \\
\hline & Lateral & $\begin{array}{l}\text { NEM: rotación, transposición, } \\
\text { otros. } \\
\text { EM: avance de periostio, cierre } \\
\text { primario }\end{array}$ & $\begin{array}{l}\text { EM o defec to extenso: Tenzel ( } 1 / 3 \text { a } 2 / 3 \text { p árpado), } \\
\text { Cuttler-Beard (>50\% párpado) }\end{array}$ & $\begin{array}{l}\text { Ptosis palpebral, } \\
\text { lagoftalmo }\end{array}$ & $\begin{array}{l}\text { Cuttler-Beard: injertode paladar } \\
\text { o cart́lago para estabilizar el } \\
\text { párpado }\end{array}$ \\
\hline & Medial & $\begin{array}{l}\text { De transposición de glabela, } \\
\text { avance horizontal, otros } \\
\text { EM: cierre primario }\end{array}$ & $\begin{array}{l}\text { EM o defec to extenso: transposición de glabela }+ \\
\text { suspensión de tendón cantal or reconstrucción, } \\
\text { Cuttler-Beard (>50\% del párpado) }\end{array}$ & $\begin{array}{l}\text { Ptosis } \\
\text { lagoftalmo }\end{array}$ & $\begin{array}{l}\text { Cuttler-Beard: injertode paladar } \\
\text { o cart́lago para estabilizar el } \\
\text { párpado }\end{array}$ \\
\hline \multirow[t]{3}{*}{ Párpado inferior } & Mediana & $\begin{array}{l}\text { NEM: rotación, romboidal, } \\
\text { avance horizontal } \\
\text { EM: avance palpebral, cierre } \\
\text { primario }\end{array}$ & $\begin{array}{l}\text { EM defecto extenso: rotación y avance de mejilla o } \\
\text { Tenzel ( } 1 / 3-2 / 3 \text { párpado), Hughes (>\%50 párpado) }\end{array}$ & & \\
\hline & Lateral & $\begin{array}{l}\text { NEM: rotación, romboidal, } \\
\text { avance horizontal } \\
\text { EM: cantolisis, catotomía y } \\
\text { cierre primario }\end{array}$ & $\begin{array}{l}\text { EM o defectos extensos: rotación y a vance de } \\
\text { mejill a o T enzel ( } 1 / 3-2 / 3 \text { del párpado), Hughes } \\
\text { (>\%50 del párpado) }\end{array}$ & & \\
\hline & Medial & $\begin{array}{l}\text { NEM: rotación, romboidal, } \\
\text { avance horizontal } \\
\text { EM: avance horizontal y cierre } \\
\text { primario }\end{array}$ & $\begin{array}{l}\text { EM od efectos extensos: rotación y avance de } \\
\text { mejill a o T enzel ( } 1 / 3-2 / 3 \text { del párpado), Hughes } \\
\text { (>\%50 del párpado) }\end{array}$ & $\begin{array}{l}\text { Daño del conducto } \\
\text { lacrimal }\end{array}$ & $\begin{array}{l}\text { Reconstrucción del conduc to } \\
\text { lacrimal }\end{array}$ \\
\hline \multirow[t]{2}{*}{ Mejilla } & Lateral & $\begin{array}{l}\text { Romboidal, cierre primario + } \\
\text { M, W o A-plastía ó de avance y } \\
\text { rotación de meji lla }\end{array}$ & Cervic ofacial de avance & $\begin{array}{l}\text { De avance cérvioo- } \\
\text { facial: Necrosis del } \\
\text { colgajo }\end{array}$ & $\begin{array}{l}\text { Cantoplastía } \\
\text { Dermabrasión, Z-plastía } \\
\text { reconstrucción con nevo colgajo } \\
\text { local, injerto de piel. }\end{array}$ \\
\hline & Medial & $\begin{array}{l}\text { Rotación y avance de mejilla, } \\
\text { Bilobulado, Colgajo Frontal de } \\
\text { traslación }\end{array}$ & Mejil la o cérvico-facial de avance y rotación; & $\begin{array}{l}\text { De mejilla o cérvico- } \\
\text { facial: Ectropion - } \\
\text { necrosis del colgajo }\end{array}$ & $\begin{array}{l}\text { Cantoplastía } \\
\text { Dermabrasión, Z-plastía - } \\
\text { reconstrucción con nevo colgajo } \\
\text { local, injerto de piel. }\end{array}$ \\
\hline \multirow[t]{4}{*}{ Nasal } & $\mathrm{Ala}$ & $\begin{array}{l}\text { Bilobulado, romboidal uo tro } \\
\text { similar }\end{array}$ & Frontal de rotación- de avance melo-labial & Necrosisdel colgajo & $\begin{array}{l}\text { Injerto de cartiago y } \\
\text { combinación de colgajos } \\
\text { modelación y adelgazamien-to } \\
\text { del colgajo en segunda instancia }\end{array}$ \\
\hline & Dorso & Avance V-Y, Bilobulado & $\begin{array}{l}\text { Frontal de rotación - rotación y avance de mejil la } \\
\text { bilateral }\end{array}$ & Necrosisdel colgajo & $\begin{array}{l}\text { Injerto de cartilago y } \\
\text { combinación de colgajos } \\
\text { modelación y adelgazamien-to } \\
\text { del colgajo en segunda instancia }\end{array}$ \\
\hline & Tip & $\begin{array}{l}\text { Bilobulado, rotación y avance } \\
\text { de glabe la }\end{array}$ & Frontal de rotación, de avance melo-labial & Necrosisdel colgajo & $\begin{array}{l}\text { Injerto de cartiago y } \\
\text { combinación de colgajos } \\
\text { modelación y adelgazamien-to } \\
\text { del colgajo en segunda instancia }\end{array}$ \\
\hline & columell a & $\begin{array}{l}\mathrm{V}-\mathrm{Y} \text { de avance, bilobulado, } \\
\text { rotación y avance de } \mathrm{m} \text { ejilla, } \\
\text { rotación y avance de glabela }\end{array}$ & Frontal de rotación & Necrosisdel colgajo & $\begin{array}{l}\text { Injerto de cartíago y } \\
\text { combinación de colgajos } \\
\text { modelación y adelgazamien-to } \\
\text { del colgajo en segunda instancia }\end{array}$ \\
\hline \multirow[t]{3}{*}{ Labio superior } & filtrum & $\begin{array}{l}\text { Solo piel o menos del } \% 50: \\
\text { cierre primario (puede incluir } \\
\text { M-plastía) }\end{array}$ & $\begin{array}{l}\text { Abbe de labio inf. (más del } 50 \% \text { de la subunidad } \\
\text { del filtro) }\end{array}$ & & \\
\hline & Lateral & De avance (medial) $<1.5 \mathrm{~cm}$ & $\begin{array}{l}\text { Nasol abial de traslación, abbe y Estandler de labio } \\
\text { inf. - combinación de Naso-labial y Abbe }\end{array}$ & $\begin{array}{l}\text { Cambio en el largo del } \\
\text { labio-microstomia }\end{array}$ & $\begin{array}{l}\text { Mantención del largo del labio- } \\
\text { comisuro-plastía }\end{array}$ \\
\hline & Berme llón & Avance de mucosa & FAMM flap, colgajode lengua, avance de mucosa & & \\
\hline \multirow[t]{2}{*}{ Labio Inferior } & & $\begin{array}{l}\text { Cierre primario A-plastía o W- } \\
\text { plastía }(<30 \%)\end{array}$ & $\begin{array}{l}\text { Abbe y Estandler (1/3 - 2/3 del labio), Karapandzic } \\
\text { o Webster-Fries ( } 2 / 3 \text { o más del labio) }\end{array}$ & Microstomi a & Comisuro-plastía \\
\hline & Berme llón & Avance de mucosa & FAMM flap, colgajode lengua, avance de mucosa & & \\
\hline
\end{tabular}




\section{REFERENCIAS BIBLIOGRÁFICAS}

Al Shetawi, A. H.; Quimby, A. \& Fernandes, R. The cervicofacial flap in cheek reconstruction: a guide for flap design. J. Oral Maxillofac. Surg., 75(12):2708.e1-2708.e6, 2017.

Ayad, T. \& Xie, L. Facial artery musculomucosal flap in head and neck reconstruction: A systematic review. Head Neck, 37(9):1375-86, 2015.

Ayad, T.; Kolb, F.; De Monès, E.; Mamelle, G.; Tan, H. K. \& Temam, S. The musculo-mucosal facial artery flap: harvesting technique and indications. Ann. Chir. Plast. Esthet., 53(6):487-94, 2008.

Benoit, A.; Hollmig, S. T. \& Leach, B. C. The nasal tip rotation flap for reconstruction of the lateral nasal tip, anterior ala, and soft triangle: the authors' experience with 55 patients. Dermatol. Surg., 43(10):1221-32, 2017.

Berlet, A. C.; Ablaza, V. J. \& Servidio, P. A refined technique for oral commissurotomy. J. Oral Maxillofac. Surg., 51(12):1400-3, 1993.

Burget, G. C. \& Menick, F. J. The subunit principle in nasal reconstruction. Plast. Reconstr. Surg., 76(2):239-47, 1985.

Burget, G. C.; Murrel, G. L. \& Toriumi, D. M. Aesthetic reconstruction of the confluence of the nose, lip, and cheek. Op. Tech. Plast. Reconstr. Surg., 5(1):76-88, 1998.

Cass, N. D. \& Terella, A. M. Reconstruction of the cheek. Facial Plast. Surg. Clin. North Am., 27(1):55-66, 2019.

Chandler, D. B. \& Gausas, R. E. Lower eyelid reconstruction. Otolaryngol. Clin. North Am., 38(5):1033-42, 2005.

Chang, E. I.; Esmaeli, B. \& Butler, C. E. Eyelid reconstruction. Plast. Reconstr. Surg., 140(5):724e-735e, 2017.

Codner, M. A.; McCord, C. D.; Mejia, J. D. \& Lalonde, D. Upper and lower eyelid reconstruction. Plast. Reconstr. Surg., 126(5):231e245e, 2010.

Colletti, G. Le mmo's flap for nasal dorsum reconstruction. J. Oral Maxillofac. Surg., 70(3):672-6, 2012.

Cox, A. \& Fort, M. Nasal reconstruction involving multiple subunit defects. Facial Plast. Surg., 33(1):58-66, 2017.

Erdogmus, S. \& Govsa, F. Anatomy of the supraorbital region and the evaluation of it for the reconstruction of facial defects. J. Craniofac. Surg., 18(1):104-12, 2007.

Faris, C.; van der Eerden, P. \& Vuyk, H. The midline central artery forehead flap: a valid alternative to supratrochlear-based forehead flaps. JAMA Facial Plast. Surg., 17(1):16-22, 2015.

Feintisch AM, Sood A, Granick M. Bilobed Flap For Nasal Reconstruction. In: Tran, T. A.; Panthaki, Z. J.; Thaller, S. R. \& Jamal, J. Hoballah Operative Dictations in Plastic and Reconstructive Surgery. Cham, Springer, 2016.

Ho, M. L.; Juliano, A.; Eisenberg, R. L. \& Moonis, G. Anatomy and pathology of the facial nerve. AJR Am. J. Roentgenol., 204(6):W612-9, 2015.

Hsiao, Y. C.; Chang, C. S. \& Zelken, J. Aesthetic refinements in forehead flap reconstruction of the Asian nose. Plastic Surgery. Plast. Surg. (Oakv.), 25(2):71-7, 2017.

Hudson, D. A. Some thoughts on choosing a Z-plasty: The Z made simple. Plast. Reconst. Surg., 106(3):665-71, 2000.

Hwang, K. Surgical anatomy of the facial nerve relating to facial rejuvenation surgery. J. Craniofacial Surg., 25(4):1476-81, 2014.

Jhamb, A. \& Mohanty, S. A technique for functional and aesthetic reconstruction of the oral commissure and buccal mucosa. Int. J. Oral Maxillofac. Surg., 39(3):287-9, 2010.

Jowett, N. \& Mlynarek, A. M. Reconstruction of cheek defects: A review of current techniques. Curr. Opin. Otolaryngol. Head Neck Surg., 18(4):244-54, 2010.

Koranda, F. C. \& Webster, R. C. Trapdoor effect in nasolabial flaps. Causes and corrections. Arch Otolaryngol., 111(7):421-4, 1985.

Larrabee, Y. C. \& Moyer, J. S. Reconstruction of Mohs defects of the lips and chin. Facial Plast. Surg. Clin. North Am., 25(3):427-42, 2017.
Luce, E. A. Upper lip reconstruction. Plast. Reconstr. Surg., 140(5):9991007, 2017.

Menick, F. J. A 10-year experience in nasal reconstruction with the threestage forehead flap. Plast. Reconstr. Surg., 109(6):1839-5, 2002.

Menick, F. J. Nasal reconstruction: forehead flap. plastic and reconstructive surgery. Plast. Reconstr. Surg., 113(6):100e-111e, 2004.

O'Reilly, A. G.; Schmitt, W. R.; Roenigk, R. K.; Moore, E. J. \& Price, D. L. Closure of scalp and forehead defects using external tissue expander. Arch. Facial Plast. Surg., 14(6):419-22, 2012.

Pepper, J. P. \& Baker, S. R. Local flaps: Cheek and lip reconstruction. JAMA Facial Plast. Surg., 15(5):374-82, 2013.

Price, D. L.; Sherris, D. A.; Bartley, G. B. \& Garrity, J. A. Forehead flap periorbital reconstruction. Arch. Facial Plast. Surg., 6(4):222-7, 2004.

Rao, J. K. \& Shende, K. S. Overview of local flaps of the face for reconstruction of cutaneous malignancies: single institutional experience of seventy cases. J. Cutan. Aesthet. Surg., 9(4):220-5, 2016.

Rodríguez-Lorenzo, A.; Audolfsson, T.; Wong, C.; Saiepour, D.; Nowinski, D. \& Rozen, S. Vascular perfusion of the facial skin: implications in allotransplantation of facial aesthetic subunits. Plast. Reconstr. Surg., 138(5):1073-9, 2016.

Roldán, J. C.; Teschke, M.; Fritzer, E.; Dunsche, A.; Härle, F.; Wiltfang, J. \& Terheyden, H. Reconstruction of the lower lip: rationale to preserve the aesthetic units of the face. Plast. Reconstr. Surg., 120(5):1231-9, 2007

Seitz, I. A. \& Gottlieb, L. J. Reconstruction of scalp and forehead defects. Clin. Plast. Surg., 36(3):355-77, 2009.

Seo, Y. J.; Hwang, C.; Choi, S. \& Oh, S. H. Midface reconstruction with various flaps based on the angular artery. J. Oral Maxillofac. Surg., 67(6):1226-33, 2009.

Singh, D. J. \& Bartlett, S. P. Aesthetic considerations in nasal reconstruction and the role of modified nasal subunits. Plast. Reconstr. Surg., 111(2):639-48, 2003.

Sokoya, M.; Inman, J. \& Ducic, Y. Scalp and forehead reconstruction. Semin. Plast. Surg., 32(2):90-4, 2018

Stein, J. D. \& Antonyshyn, O. M. Aesthetic eyelid reconstruction. Clin. Plast. Surg., 36(3):379-97, 2009.

van Leeuwen, A. C.; The, A.; Moolenburgh, S. E.; de Haas, E. R. M. \& Mureau, M. A. M. A retrospective review of reconstructive options and outcomes of 202 cases large facial mohs micrographic surgical defects, based on the aesthetic unit involved. J. Cutan. Med. Surg., 19(6):580-7 2015.

Wo, L. M.; Singh, D. \& Thaller, S. R. Local flaps for reconstruction in the head and neck. J. Craniofac. Surg., 2021. DOI: https://www.doi.org/ 10.1097/SCS.0000000000007641.

Ye, W.; Hu, J.; Zhu, H.; Zhang, C. \& Zhang, Z. Application of modified Karapandzic flaps in large lower lip defect reconstruction. J. Oral Maxillofac. Surg., 72(10):2077-82, 2014.

Yoon, T.; Benito-Ruiz, J.; García-Díez, E. \& Serra-Renom, J. M. Our algorithm for nasal reconstruction. J. Plast. Reconstr. Aesth. Surg., 59(3):239-47, 2006.

Yotsuyanagi, T.; Yamashita, K.; Urushidate, S.; Yokoi, K. \& Sawada, Y. Reconstruction of large nasal defects with a combination of local flaps based on the aesthetic subunit principle. Plast. Reconstr. Surg., 107(6):1358-62, 2001.

Dirección para correspondencia:

Claudio Huentequeo Molina

Servicio de Cirugía Oral y Maxilofacial

Barrosarana 820, Lautaro, Chile

Hospital Dr. Abraham Godoy Peña

Lautaro - CHILE

E-mail: claudiohuentequeo@gmail.com 